\title{
Cómo aprenden los maestros de Educación Primaria la enseñanza y el aprendizaje de la Geometría
}

\author{
GLORIA SÁnCHEZ-MATAMOROS García \\ Universidad de Sevilla \\ Facultad de Ciencias de la Educación \\ Departamento de Didáctica de las Matemáticas. \\ gsanchezmatamoros@us.es \\ ORCID: https://orcid.org/0000-0002-7502-7924 \\ D.0.I.: http://dx.doi.org/10.12795/JDU.2018.i01.44 \\ Pp.: 784-800
}

\section{Resumen}

Se realizó un ciclo de mejora en la asignatura: Didáctica de las Matemáticas específicas para maestro del Grado en Educación Primaria, llevando a cabo sesiones en la docencia teórica, mediante el modelo metodológico basado en la reelaboración de ideas por parte de los estudiantes para maestro, para conseguir un aprendizaje significativo en relación al aprendizaje y a la enseñanza de la Geometría en Educación Primaria. Los resultados obtenidos muestran cambios significativos en relación a cómo los estudiantes para maestro consideran el aprendizaje de la clasificación de cuadriláteros en el alumnado de Primaria.

Palabras clave: Didáctica de las Matemáticas, Grado en Educación Primaria, Geometría, Docencia universitaria, Experimentación Docente Universitaria. 


\section{Breve descripción del contexto}

El ciclo de mejora se realizó en la asignatura de Didáctica de las Matemáticas específicas para maestro del Grado de Educación Primaria. Dicha asignatura es obligatoria de 2 o curso del Grado de Educación Primaria y la cursa un alumnado que ya ha realizado anteriormente otra asignatura obligatoria, Matemáticas Específicas para Maestros del 1ํ curso del Grado de Educación Primaria. Tanto la asignatura de primero como la de segundo están divididas en distintos módulos de enseñanza, el ciclo de mejora lo realicé en el módulo dedicado a la Geometría.

En el departamento de Didáctica de las Matemáticas, en la asignatura de Didáctica de las Matemáticas específicas para maestro, distinguimos en cada módulo de enseñanza las siguientes partes: contenido, aprendizaje y enseñanza. Respecto a los contenidos, siempre se tratan de forma muy sucinta, por tener la asignatura de 10 de grado de Educación Primaria dedicada a ello de forma explícita (Matemáticas específica para maestros de 1o de Grado de Educación Primaria). Tratándose de forma mucho más extensa el aprendizaje y la enseñanza del contenido en cuestión que es lo propio de la asignatura de 2o. Las clases dedicadas al módulo de Geometría comenzaron el 19 de marzo y finalizaron el 11 de mayo.

\section{Diseño previo del Ciclo de Mejora Docente}

\section{Mapa de contenidos y problemas}

En el módulo de Geometría donde he realizado mi ciclo de mejora, trabajamos con el modelo de Van Hiele (Jaime y Gutiérrez, 1990) tanto para el aprendizaje como para la enseñanza de este tópico matemático (Figuras 1 y 2). 


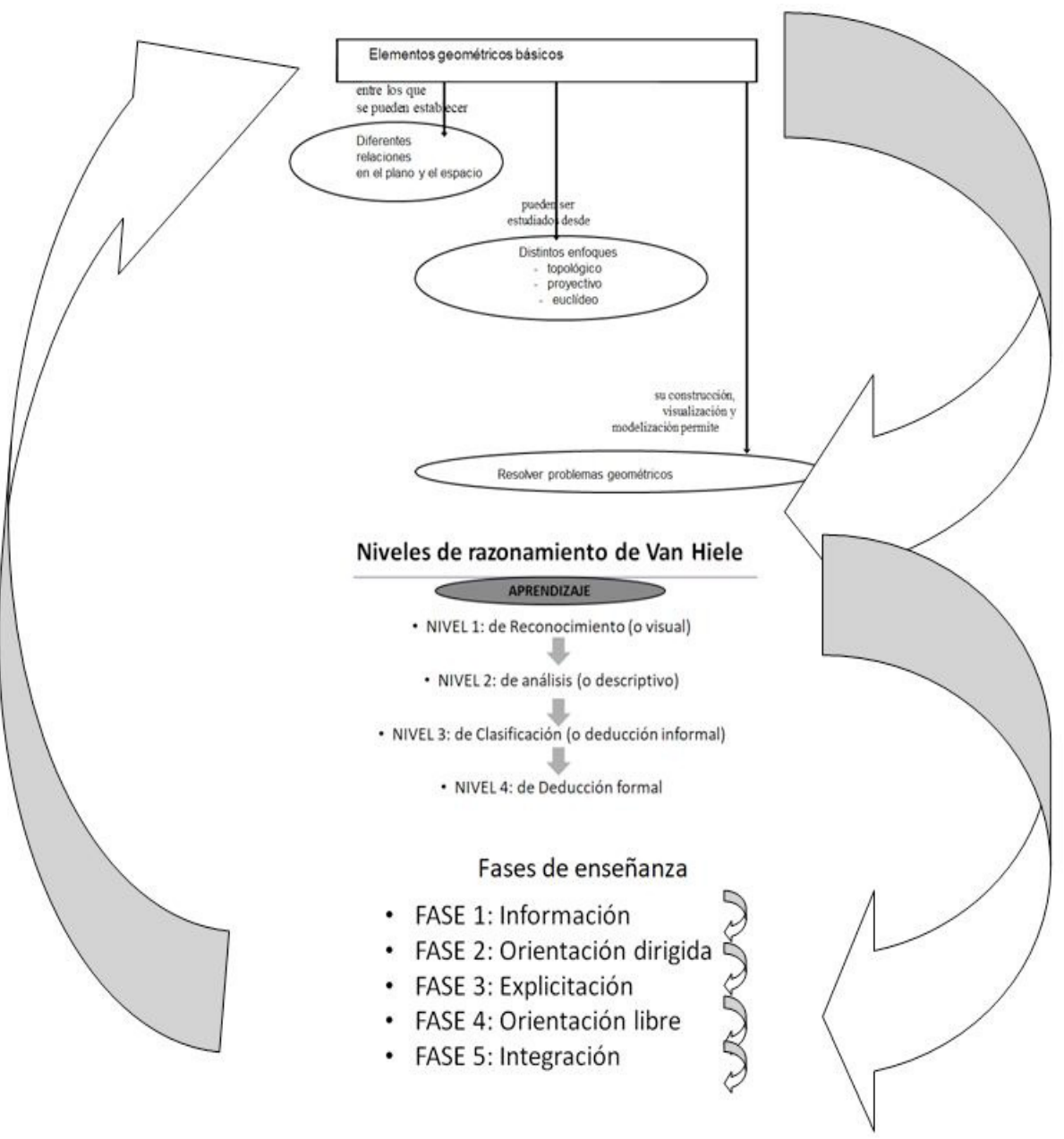

Figura 1. Mapa conceptual del módulo de Geometría

Jornadas de Formación e Innovación Docente del Profesorado | № 1 (2018) 


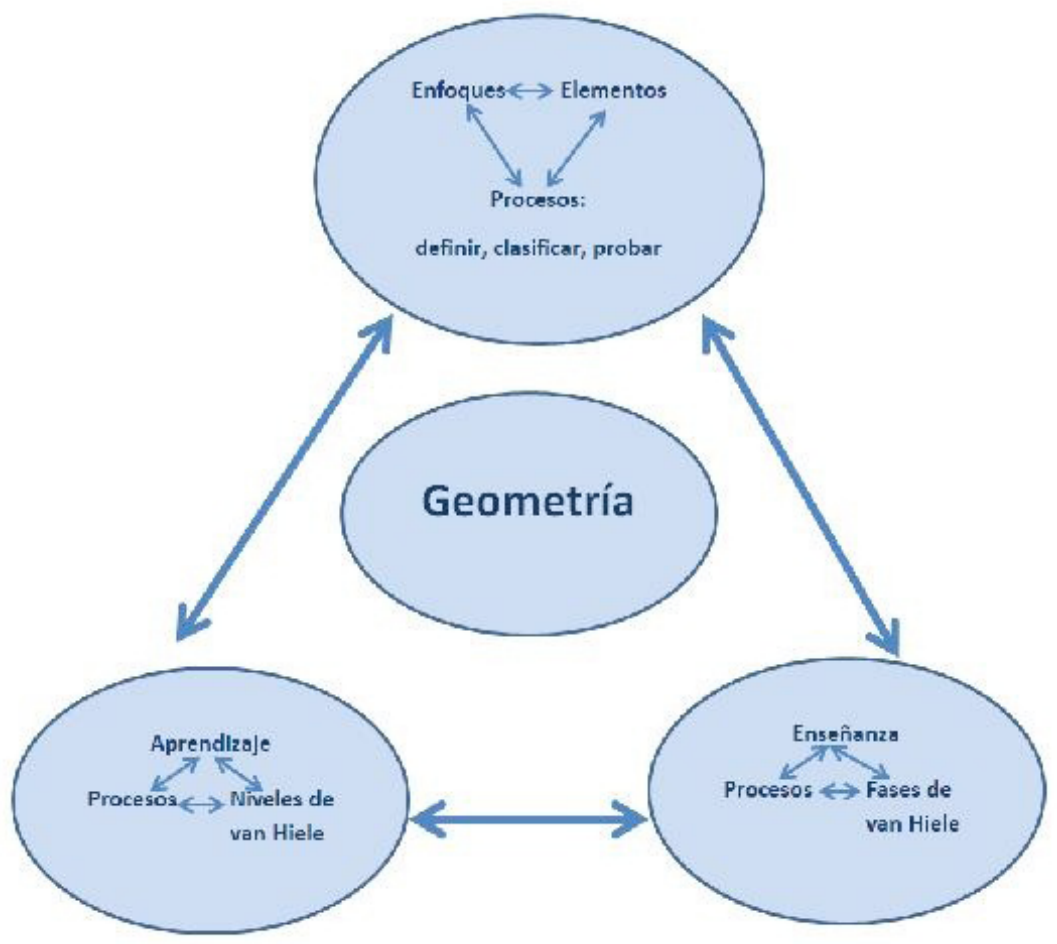

Figura 2. Sistema de organización de los contenidos (adaptada de Porlán, 2017)

\section{Modelo metodológico posible y secuencia de actividades}

El modelo metodológico llevado a cabo en dicho ciclo de mejora ha sido un Modelo basado en la reelaboración de las ideas de los estudiantes. Las fases fundamentales de este modelo que quiero recoger en mi práctica habitual son (figura 3):

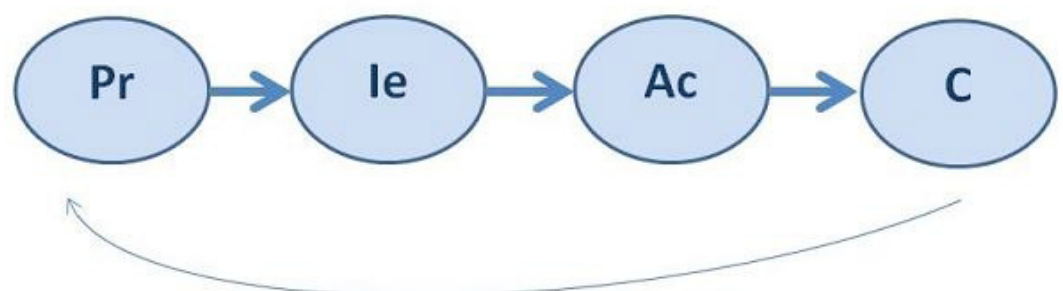

Figura 3. Esquema de las fases del modelo (adaptado de Porlán, 2017)

Jornadas de Formación e Innovación Docente del Profesorado | № 1 (2018) (c) (i) $\odot-$ Esta obra se distribuye con la licencia Creative Commons 
Pr: Planteamiento del problema: plantear un problema de investigación relacionado con el módulo de enseñanza, relacionado con la Geometría: elementos matemáticos implicados y características de la comprensión que se deben poner de manifiesto en un estudiante que comprende los procesos de definir y clasificar figuras geométricas; y tipos de tareas que permiten progresar en el aprendizaje de la definición y clasificación de figuras geométricas.

le: Toma de conciencia y expresión por parte de los estudiantes de sus ideas respecto al problema: Testar las ideas previas de los estudiantes para conocer su punto de partida (con las mismas cuestiones al final).

Ac: Puesta en práctica de actividades de contraste que las pongan en cuestión: Vincular sus ideas al módulo de enseñanza a través de distintos sub-problemas y/ o sub-preguntas; elaborar una secuencia de actividades para cada sub-problema y/ o sub-preguntas; entre cada sub-problema y/ o sub-pregunta, testar a los estudiantes, para conocer cómo va evolucionando su aprendizaje y poder detectar dificultades.

C: Elaboración de conclusiones sobre ideas iniciales y finales, y sobre lo aprendido en el proceso: Finalizar dando respuesta al problema de investigación a través de la reelaboración de ideas previas por parte de los estudiantes que quedaron recogidas en los informes elaborados.

\section{Secuencia de actividades}

La secuencia de actividades fue la siguiente: 
Cronograma de Actividades desarrolladas en el Ciclo de Mejora

\begin{tabular}{|c|c|c|c|}
\hline Semana & Jueves & Viernes & Actividad \\
\hline Semana 1 & $\begin{array}{l}\text { Tarea profesional } \\
\text { (ideas previas) }\end{array}$ & $\begin{array}{l}\text { Continuación de la } \\
\text { tarea profesional }\end{array}$ & $\begin{array}{l}\text { Tarea profesional } \\
\text { (anexo 1) }\end{array}$ \\
\hline Semana 2 & $\begin{array}{l}\text { Documentos teó- } \\
\text { ricos sobre cómo } \\
\text { el alumnado de } \\
\text { Educación Prima- } \\
\text { ria progresa en el } \\
\text { aprendizaje de la } \\
\text { Geometría }\end{array}$ & $\begin{array}{l}\text { Reflexión de dis- } \\
\text { tintas situacio- } \\
\text { nes de enseñanza } \\
\text { aprendizaje de } \\
\text { aula }\end{array}$ & $\begin{array}{l}\text { Tareas sobre el } \\
\text { aprendizaje de la } \\
\text { clasificación de fi- } \\
\text { guras planas }\end{array}$ \\
\hline Semana 3 & $\begin{array}{l}\text { Documentos teó- } \\
\text { ricos sobre tipo- } \\
\text { logía de tareas en } \\
\text { relación con el } \\
\text { aprendizaje de la } \\
\text { Geometría }\end{array}$ & $\begin{array}{l}\text { Planificación de } \\
\text { una sesión de } \\
\text { aula }\end{array}$ & $\begin{array}{l}\text { Diseño de tareas } \\
\text { relacionadas con } \\
\text { la clasificación de } \\
\text { figuras planas }\end{array}$ \\
\hline Semana 4 & $\begin{array}{l}\text { Documentos teó- } \\
\text { ricos relacionando } \\
\text { los niveles de } \\
\text { comprensión con } \\
\text { posibles tipos de } \\
\text { tareas }\end{array}$ & $\begin{array}{l}\text { Reflexión de } \\
\text { distintas si- } \\
\text { tuaciones de } \\
\text { enseñanza-apren- } \\
\text { dizaje de aula y } \\
\text { posible planifica- } \\
\text { ción de una sesión } \\
\text { de aula vinculada } \\
\text { a situaciones de } \\
\text { enseñanza-apren- } \\
\text { dizaje planteadas }\end{array}$ & $\begin{array}{l}\text { Diseño de tareas } \\
\text { mostrando obje- } \\
\text { tivos de aprendi- } \\
\text { zaje coherentes al } \\
\text { nivel de compren- } \\
\text { sión anticipado } \\
\text { o identificado en } \\
\text { distintas situacio- } \\
\text { nes de enseñanza } \\
\text { aprendizaje de la } \\
\text { geometria }\end{array}$ \\
\hline Semana 5 & $\begin{array}{l}\text { Reflexión de los } \\
\text { documentos teó- } \\
\text { ricos tratados a lo } \\
\text { largo del módulo }\end{array}$ & $\begin{array}{l}\text { Reelaboración de } \\
\text { la tarea profesio- } \\
\text { nal tratada en la } \\
\text { semana } 1\end{array}$ & $\begin{array}{l}\text { Resolución de la } \\
\text { tarea profesio- } \\
\text { nal de la semana } \\
1 \text { desde los do- } \\
\text { cumentos teóri- } \\
\text { cos trabajados en } \\
\text { las tres sesiones } \\
\text { anteriores }\end{array}$ \\
\hline
\end{tabular}




\section{Tarea inicial-final para hacer el seguimiento de la evolución de los estudiantes para maestro.}

Con el objetivo de conocer el punto de partida de cada estudiante en relación con los contenidos a impartir, se les pasó a los estudiantes una tarea profesional sobre la enseñanza y el aprendizaje de la clasificación de cuadriláteros. Esta misma tarea profesional fue contestada por los estudiantes al finalizar el módulo de enseñanza con el fin de determinar el progreso en el aprendizaje logrado por cada estudiante en relación con el módulo de enseñanza. En el anexo 1 se muestra la tarea profesional propuesta (adaptada de Llinares, Fernández y Sánchez-Matamoros, 2016) a los estudiantes que deberán cumplimentar antes y después del ciclo de mejora. Estas tareas serán anónimas, y se codificarán.

\section{Aplicación del ciclo de mejora}

\section{Relato resumido de las sesiones}

En el ciclo de mejora llevado a cabo, los estudiantes se mostraron sorprendidos por la propuesta de una primera tarea profesional en la que ellos debían anticipar posibles respuestas del alumnado de Educación Primaria en relación a la comprensión de los paralelogramos, sin haber abordado previamente la enseñanza y aprendizaje de este contenido matemático. Se les explicó brevemente que debían entregar la resolución de esta actividad pues en la última semana volverían a trabajar con dicha actividad y tendrian la oportunidad de reelaborar el informe hecho con el objetivo de que pudieran reflexionar sobre lo aprendido en el módulo.

Los estudiantes tuvieron en las sesiones de aula un papel activo, se les presentaron distintas situaciones de 
aula a través de vídeos y respuestas escritas de alumnado de Educación Primaria. Y en algunas otras ocasiones fueron ellos mismos los que recogieron estas respuestas escritas de los estudiantes de Educación Primaria y los que realizaron entrevistas semiestructuradas a partir de las respuestas escritas para determinar las características de la comprensión que se estaban poniendo de manifiesto por parte del alumnado de Primaria en sus respuestas. Por último, debieron decidir qué nueva tarea se les debía proponer a estos alumnos de Educación Primaria y con qué objetivo de aprendizaje. En otras ocasiones, se les pidió a los estudiantes para maestro que anticiparan posibles respuestas de alumnos de Primaria a una determinada tarea o que planifiquen una posible sesión de aula.

Todas estas situaciones les resultaron sorpresivas y novedosas. Y les hicieron reflexionar sobre todo el proceso de enseñanza aprendizaje y la complejidad que dicho proceso conlleva. En general, el clima de trabajo que se creó en el aula fue muy bueno y se sintieron bastante implicados en el tema. Sin embargo, hay que destacar que las mayores dificultades se han encontrado en el diseño de tareas cuando se deben relacionar con las características de la comprensión identificadas en el alumnado en las diferentes situaciones de enseñanza aprendizaje planteadas a través de videos o respuestas escritas.

\section{Evaluación del aprendizaje de los estudiantes}

En este Ciclo de Mejora utilizamos como instrumento de evaluación del proceso de aprendizaje el análisis de las respuestas a la tarea profesional considerada antes y después del módulo de enseñanza. Para ello hemos elaborado una rúbrica de evaluación en la que se han tenido en cuenta los distintos aspectos trabajados en el módulo de enseñanza en relación con el aprendizaje y la enseñanza de los cuadriláteros en Educación Primaria. A través de dicha rúbrica se analizan las diferencias entre las 
valoraciones iniciales y las finales y podemos apreciar si ha habido cambios en los porcentajes de la escalera diseñada. Mostramos tres gráficas comparativas correspondientes a cada una de las preguntas que debían contestar en la tarea profesional en relación a las características de la comprensión consideradas en los alumnos de primaria por los estudiantes en sus respuestas (gráficas 1 y 2) y las nuevas propuestas de tareas realizadas por los mismos (gráfico 3) antes y después del módulo de enseñanza. Sólo hemos considerados aquellos estudiantes que habían contestado ambos cuestionarios para exponer los gráficos de los resultados, en total 34.

Tabla 2

Rúbrica de evaluación para la tarea profesional

\begin{tabular}{|c|c|c|c|c|}
\hline Cuestiones & $100 \%$ & $75 \%$ & $50 \%$ & $25 \%$ \\
\hline $\begin{array}{l}\text { Considera las } \\
\text { características } \\
\text { de la clasifica- } \\
\text { ción y definición } \\
\text { de cuadriláteros } \\
\text { para anticipar la } \\
\text { respuesta de un } \\
\text { estudiante que } \\
\text { alcanza el obje- } \\
\text { tivo de aprendi- } \\
\text { zaje (Marcos) } \\
(35 \%)\end{array}$ & $\begin{array}{l}\text { Considera } \\
\text { diferentes ti- } \\
\text { pos de de- } \\
\text { finiciones y } \\
\text { clasificacio- } \\
\text { nes posibles } \\
\text { en relación } \\
\text { con los pa- } \\
\text { ralelogramos } \\
\text { fijándose } \\
\text { en las pro- } \\
\text { piedades } \\
\text { de los mis- } \\
\text { mos y rela- } \\
\text { ciones entre } \\
\text { propiedades. }\end{array}$ & $\begin{array}{l}\text { Considera } \\
\text { diferentes ti- } \\
\text { pos de cla- } \\
\text { sificaciones } \\
\text { posibles en } \\
\text { relación con } \\
\text { los parale- } \\
\text { logramos fi- } \\
\text { jándose en } \\
\text { las propie- } \\
\text { dades de } \\
\text { los mis- } \\
\text { mos y rela- } \\
\text { ciones entre } \\
\text { propiedades. }\end{array}$ & $\begin{array}{l}\text { Considera } \\
\text { definiciones } \\
\text { en relación } \\
\text { a una sola } \\
\text { clasificación } \\
\text { de los para- } \\
\text { lelogramos } \\
\text { fijándose } \\
\text { en las pro- } \\
\text { piedades } \\
\text { de los mis- } \\
\text { mos y rela- } \\
\text { ciones entre } \\
\text { propiedades. }\end{array}$ & $\begin{array}{l}\text { Considera } \\
\text { una sola cla- } \\
\text { sificación en } \\
\text { relación con } \\
\text { los parale- } \\
\text { logramos fi- } \\
\text { jándose en } \\
\text { las propie- } \\
\text { dades de } \\
\text { los mis- } \\
\text { mos y rela- } \\
\text { ciones entre } \\
\text { propiedades. }\end{array}$ \\
\hline
\end{tabular}

Jornadas de Formación e Innovación Docente del Profesorado | № 1 (2018) Esta obra se distribuye con la licencia Creative Commons 


\begin{tabular}{|c|c|c|c|c|}
\hline $\begin{array}{l}\text { Considera las } \\
\text { características } \\
\text { de la clasifica- } \\
\text { ción y definición } \\
\text { de cuadriláte- } \\
\text { ros para antici- } \\
\text { par la respuesta } \\
\text { de un estu- } \\
\text { diante que no } \\
\text { alcanza el obje- } \\
\text { tivo de aprendi- } \\
\text { zaje (Isabel) } \\
\text { (35\%) }\end{array}$ & $\begin{array}{l}\text { Considera } \\
\text { diferentes ti- } \\
\text { pos de de- } \\
\text { finiciones y } \\
\text { clasificacio- } \\
\text { nes posibles } \\
\text { en relación } \\
\text { con los pa- } \\
\text { ralelogramos } \\
\text { fijándose } \\
\text { en las pro- } \\
\text { piedades de } \\
\text { los mismos } \\
\text { y posibles } \\
\text { imágenes } \\
\text { prototípi- } \\
\text { cas de los } \\
\text { mismos. }\end{array}$ & $\begin{array}{l}\text { Considera } \\
\text { diferentes ti- } \\
\text { pos de cla- } \\
\text { sificaciones } \\
\text { posibles en } \\
\text { relación con } \\
\text { los parale- } \\
\text { logramos fi- } \\
\text { jándose en } \\
\text { las propie- } \\
\text { dades de } \\
\text { los mismos } \\
\text { y posibles } \\
\text { imágenes } \\
\text { prototípi- } \\
\text { cas de los } \\
\text { mismos. }\end{array}$ & $\begin{array}{l}\text { Considera } \\
\text { definiciones } \\
\text { en relación a } \\
\text { una sola cla- } \\
\text { sificación en } \\
\text { relación con } \\
\text { los parale- } \\
\text { logramos fi- } \\
\text { jándose en } \\
\text { las propie- } \\
\text { dades de } \\
\text { los mismos } \\
\text { y posibles } \\
\text { imágenes } \\
\text { prototípi- } \\
\text { cas de los } \\
\text { mismos. }\end{array}$ & $\begin{array}{l}\text { Considera } \\
\text { una sola cla- } \\
\text { sificación en } \\
\text { relación con } \\
\text { los parale- } \\
\text { logramos fi- } \\
\text { jándose en } \\
\text { las propie- } \\
\text { dades de } \\
\text { los mismos } \\
\text { y posibles } \\
\text { imágenes } \\
\text { prototípi- } \\
\text { cas de los } \\
\text { mismos. }\end{array}$ \\
\hline $\begin{array}{l}\text { Propone nuevas } \\
\text { tareas para am- } \\
\text { bos estudiantes } \\
(30 \%)\end{array}$ & $\begin{array}{l}\text { Propone } \\
\text { nuevas ta- } \\
\text { reas para } \\
\text { que los dos } \\
\text { estudiantes } \\
\text { sigan pro- } \\
\text { gresando en } \\
\text { el aprendi- } \\
\text { zaje de los } \\
\text { cuadriláte- } \\
\text { ros acorde } \\
\text { con la com- } \\
\text { prensión an- } \\
\text { ticipada en } \\
\text { cada uno de } \\
\text { ellos. }\end{array}$ & $\begin{array}{l}\text { Propone } \\
\text { nuevas ta- } \\
\text { reas para } \\
\text { que Isabel } \\
\text { siga progre- } \\
\text { sando en } \\
\text { el aprendi- } \\
\text { zaje de los } \\
\text { cuadriláte- } \\
\text { ros acorde } \\
\text { con la com- } \\
\text { prensión an- } \\
\text { ticipada y } \\
\text { para Marcos } \\
\text { una tarea de } \\
\text { refuerzo. }\end{array}$ & $\begin{array}{l}\text { Propone una } \\
\text { nueva ta- } \\
\text { rea sólo } \\
\text { para uno } \\
\text { de los dos } \\
\text { estudian- } \\
\text { tes (Mar- } \\
\text { cos o Isabel) } \\
\text { acorde con } \\
\text { la compren- } \\
\text { sión antici- } \\
\text { pada en el } \\
\text { estudiante } \\
\text { para que } \\
\text { siga progre- } \\
\text { sando en el } \\
\text { aprendizaje } \\
\text { de la clasi- } \\
\text { ficación de } \\
\text { cuadriláteros. }\end{array}$ & $\begin{array}{l}\text { Propone una } \\
\text { nueva tarea } \\
\text { para los dos } \\
\text { estudian- } \\
\text { tes (Mar- } \\
\text { cos e Isabel) } \\
\text { sin tener en } \\
\text { cuenta las } \\
\text { caracterís- } \\
\text { ticas de la } \\
\text { comprensión } \\
\text { anticipada } \\
\text { en ellos. }\end{array}$ \\
\hline
\end{tabular}

A continuación se muestran las tres gráficas correspondientes a las respuestas de los estudiantes antes y después del módulo de enseñanza para cada una de las tres cuestiones de la tarea profesional según la escalera de aprendizaje considerada. 


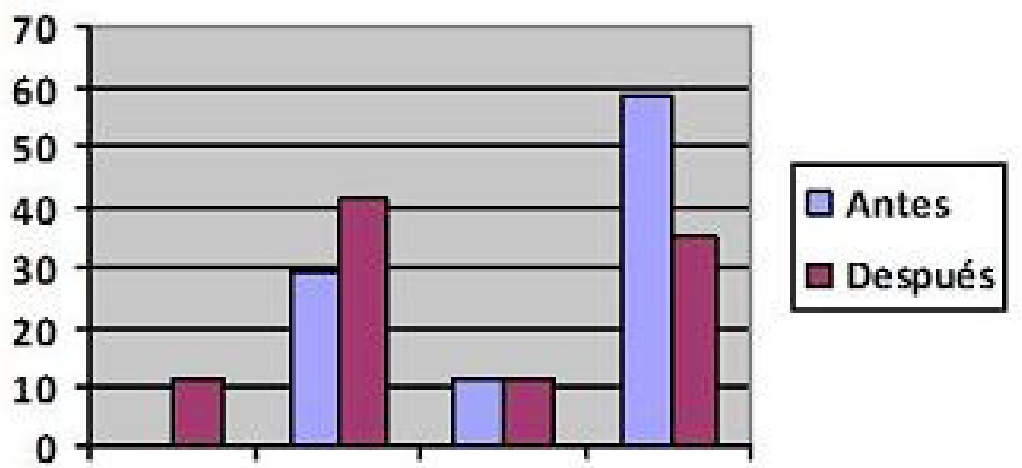

escala A escalaB escalaC escalaD $\begin{array}{llll}(100 \%) & (75 \%) & (50 \%) & (25 \%)\end{array}$

Gráfica 1. Escalera de aprendizaje inicial y final en la pregunta 1 de la tarea profesional.

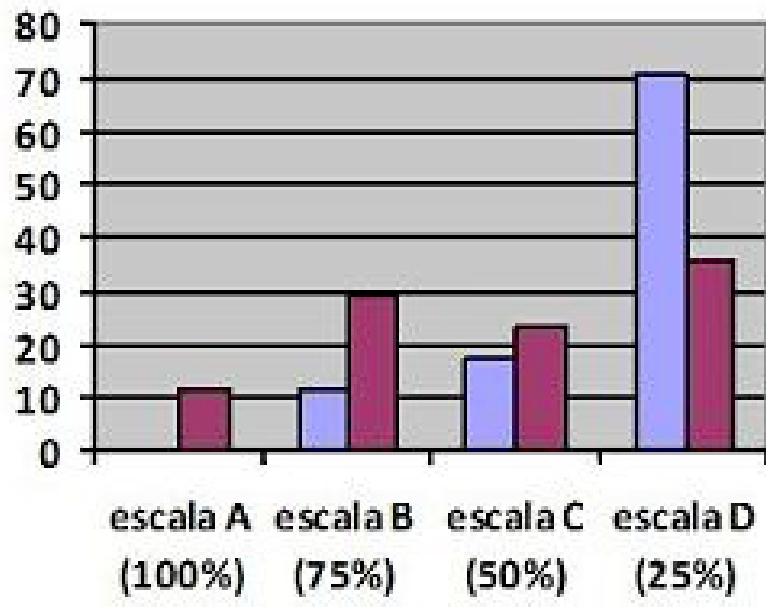

antes

$\square$ Después

Gráfica 2. Escalera de aprendizaje inicial y final en la pregunta 2 de la tarea profesional.

Como puede observarse en las tres gráficas elaboradas con los datos de las respuestas de los estudiantes antes y después del módulo de enseñanza se pueden apreciar cambios en las ideas de los estudiantes en relación al aprendizaje (gráficas 1 y 2) y a la enseñanza de la geometría (gráfica 3), en particular con la clasificación de cuadriláteros para alumnos de Primaria.

Jornadas de Formación e Innovación Docente del Profesorado I № 1 (2018)
Esta obra se distribuye con la licencia Creative Commons Reconocimiento-NoComercial-SinObraDerivada 
0

\section{escala A escala B escalaC escalaD $(100 \%) \quad(75 \%) \quad(50 \%) \quad(25 \%)$}

Gráfica 3. Escalera de aprendizaje inicial y final en la pregunta 3 de la tarea profesional.

Sin embargo, hay que señalar que estos cambios han sido más significativos en el aprendizaje que en la enseñanza, ya que en el aprendizaje podemos apreciar estos cambios en el $100 \%$ de la muestra, es decir en los 34 estudiantes, donde más del $50 \%$ se han situado entre la escala A y la B.

Respecto a la enseñanza sólo podemos observar cambios en 10 de los 34 estudiantes, el resto, 24 estudiantes, no han sido capaces de proponer tareas acordes a las características de la comprensión anticipadas para los alumnos de primaria en relación con la clasificación de cuadriláteros. Esto puede ser debido a que el desarrollo de la competencia de la mirada profesional requiere tres destrezas interrelacionadas: anticipar o identificar estrategias en la resolución de problemas por parte de los estudiantes, interpretar la comprensión a partir de las estrategias y decidir nuevas tareas para que los alumnos sigan progresando en su aprendizaje (Jacobs, Lamb y Philipp; 2010). Los estudiantes han empezado a relacionar dos de estas tres destrezas (anticipar o identificar estrategias en la resolución de problemas por parte de los alumnos e interpretar la 
comprensión a partir de dichas estrategias). Sin embargo, tan sólo 10 de los 34 estudiantes llegan a proponer tareas acordes a la comprensión de los alumnos y con objetivos de aprendizaje coherentes. Este hecho hace que se considere la dificultad de la interrelación de las tres destrezas por parte del estudiante.

\section{Evaluación del Ciclo de Mejora Docente puesto en práctica}

\section{Cuestiones a mantener y cambios a introducir para un futuro Ciclo de Mejora}

A la vista de los resultados obtenidos sería conveniente introducir en un próximo ciclo de mejora la posibilidad de retomar la tarea profesional además de en el inicio y en el final del módulo de enseñanza, en un momento intermedio del módulo de enseñanza con el fin de ir observando los cambios en el aprendizaje de los estudiantes para maestro a lo largo del módulo evitando de esta forma, las posibles dificultades de aprendizaje en los estudiantes para maestro, como en este caso ha ocurrido con la propuesta de tareas.

Aspectos de la experiencia que se pretenden incorporar a toda la práctica docente habitual

En mi práctica docente continuaré con el diseño metodológico planteado basado en la reelaboración de ideas por parte de los estudiantes para conseguir un aprendizaje significativo. Pretendo cambiar los contenidos para desarrollar una docencia participativa basada en la reflexión de lo aprendido para poder conseguir con ello la reelaboración de las propias ideas a lo largo de todo el módulo de enseñanza por parte de los estudiantes para maestro de Educación Primaria. 


\section{Principios didácticos argumentados que han guiado la experiencia y que deben permanecer en el futuro}

Los principios didácticos que han guiado la experiencia

y que deben permanecer en el futuro son los siguientes:

- Previo a cada módulo de enseñanza diseñaremos o plantearemos una tarea profesional inicial para que a partir de la reflexión el estudiante para maestro puede reelaborar sus ideas iniciales a lo largo del módulo de enseñanza a través de los documentos teóricos facilitados en el mismo.

- Elaborar mapas conceptuales y organizar las secuencias de tareas.

- Dar tiempo de trabajo al alumnado.

- Proponer tareas profesionales que les permitan la adquisición de la competencia con una perspectiva profesional.

- Diversificar el tipo de tareas proponiéndoles tareas profesionales de anticipar y de identificar.

- Establecer algún instrumento de evaluación del profesor. 


\section{Referencias bibliográficas}

Jacobs, V. R., Lamb, L.C. y Philipp, R. A. (2010). Professional noticing of children's mathematical thinking. Journal for Research in Mathematics Education, 41(2), 169-202.

Jaime, A. y Gutiérrez, A. (1990). Una propuesta de fundamentación para la enseñanza de la geometría: El modelo de van Hiele. En S. Llinares y M.V. Sánchez (Eds.), Teoría y práctica en educación matemática (pp. 295384). Sevilla: Alfar.

Llinares, S., Fernández C. y Sánchez-Matamoros, G. (2016) Changes in how prospective teachers anticipate secondary students' answers. Eurasia Journal of Mathematics, Science \& Technology Education, 12(8), 2155-2170 doi: 10.12973/eurasia.2016.1295a

Porlán, R. (2017). Enseñanza Universitaria. Cómo mejorarla. Madrid: Editorial Morata.

Jornadas de Formación e Innovación Docente del Profesorado | № 1 (2018) Esta obra se distribuye con la licencia Creative Commons 


\section{Anexo 1}

\section{TAREA PROFESIONAL}

Supón que eres maestro/a de matemáticas de 60 de Primaria y has completado diferentes clases sobre la clasificación de cuadriláteros, con el siguiente objetivo: "Los estudiantes comprenderán la clasificación y definición de cuadriláteros".

\section{Problema}

2.1. Observa las figuras y completa a continuación el cuadro, poniendo Sí o NO en las casillas vacías:

Figura 4. Paralelogramos

\begin{tabular}{||l|l|l|l|l|}
\hline & Cuadrado & Rectángulo & Rombo & Romboide \\
\hline Los cuatro lados son iguales & & & & \\
\hline $\begin{array}{l}\text { Los cuatro ángulos son } \\
\text { iguales }\end{array}$ & & & & \\
\hline $\begin{array}{l}\text { Los lados opuestos son } \\
\text { iguales }\end{array}$ & & & & \\
\hline Las diagonales son iguales & & & & \\
\hline $\begin{array}{l}\text { Las diagonales se cortan en } \\
\text { el punto medio }\end{array}$ & & & & \\
\hline $\begin{array}{l}\text { Las diagonales forman án- } \\
\text { gulo recto }\end{array}$ & & & & \\
\hline
\end{tabular}

2.2. Indica semejanzas y diferencias respecto de las diagonales entre:
a) rectángulo y cuadrado
b) rombo y rectángulo
c) rombo y cuadrado
d) rectángulo y romboide
e) cuadrado y romboide
f) rombo y romboide

2.3. ¿Cómo se clasifican los paralelogramos si se toma como criterio las diagonales?

Justifica la respuesta 


\section{Marcos e Isabel son dos estudiantes de tu clase.}

A) Imagina que Marcos ha alcanzado el objetivo que te has planteado. Explica cómo Marcos respondería el problema, indicando qué tiene que hacer y decir exactamente Marcos para convencerte de que comprende la clasificación de paralelogramos. Justifica tus respuestas desde los elementos matemáticos implicados y características de la comprensión que se pondrían de manifiesto por parte Marcos.

B) Y que Isabel no ha alcanzado el objetivo que te has planteado. Explica cómo Isabel respondería el problema, indicando qué tiene que hacer y decir exactamente para que consideres que sólo muestra algunas características de la comprensión pero no todas. Justifica tus respuestas desde los elementos matemáticos implicados y características de la comprensión que se pondrían de manifiesto por parte de Isabel.

c) Plantea una tarea nueva para Marcos y otra para Isabel que les permita seguir progresando en su aprendizaje indicando su demanda cognitiva. Justifica cada una de ellas. 